УДК 8

DOI $10.21661 / \mathrm{r}-116392$

В.Г. Лядский

ОТ СОЛДАТА ДО МАРШАЛА:

ПРОИСХОЖДЕНИЕ ВОИНСКИХ ЗВАНИЙ ФРАНЦУЗСКОЙ АРМИИ

Аннотация: в данной статье рассматривается один из фрагментов лексической системы франиузского языка - происхождение терминов, обозначающุих воинские звания в вооруженных силах Франции. Этимологический анализ осуществляется в тесной связи с рассмотрением конкретной исторической обстановки, порождавщей необходимость возникновения подобных единии языка. Автором намечаются практические основы сопоставительного изучения способов лексического обозначения воинских званий в основных европейских языках, в том числе и в русском языке.

Ключевые слова: франиузский язык, лексическая система языка, воинские звания, франиузская армия, историческая обстановка, сопоставительный анализ, способы лексического обозначения воинских званий.

\title{
V.G. Lyadsky
}

\section{FROM SOLDIER TO MARSHAL: THE ORIGIN OF THE RANKS OF THE FRENCH ARMY}

Abstract: this article discusses one of the fragments of the lexical system of the French language - the origin of terms denoting military ranks in the armed forces of France. The etymological analysis is carried out in close connection with the concrete historical situation which gave rise to the need of such language units. The author outlines the practical basis of the comparative study of the ways of lexical designation of ranks in the major European languages, including Russian.

Keywords: French language, lexical system, military ranks, the French army, historic setting, benchmarking, ways of lexical designation of ranks. 
Исследования, имеющие целью рассмотрение происхождения слова и эволюции его значения в пределах одного и того же языка, составление «этимологической биографий» слова, являлись и являются одной из основных задач лингвистики. Проблемы соотнесенности языковых единиц с реалиями окружающего нас мира (так называемой «предметной соотнесенности»), условия возникновения новых слов и изменения значения уже существующих в связи с углублением познания человеком действительности и совершенствованием его деятельности в различных аспектах широко и подробно описаны в специальной литературе [1].

В настоящее время семантика и этимология располагают развитой концептуальной базой и детально разработанными методами исследований. Механизм утраты языком одних слов и образования новых, особенности переориентации слова на выражение новых лексических значений проанализированы весьма подробно и полно.

В лингвистической литературе наличие денотативного компонента значения языковых единиц проиллюстрировано массой конкретных примеров, взятых из истории развития различных языков (особенно примечательны в этом отношении специальные термины, которые появляются в языке в ответ на насущную потребность обозначить вновь возникшие реалии, явления, предметы, не имевшие до этого названий).

В данной статье сделана попытка пополнить уже существующий фактический материал примерами из области французской военной терминологии, и в частности, примерами образования слов, обозначающих воинские звания во французских вооруженных силах.

Методом исследования избрано рассмотрение конкретных исторических условий, в которых появлялись новые для французского общества и армии реалии и возникала соответствующая потребность в их обозначении лексическими средствами языка. Как будет показано ниже, во французском языке это происходило как за счет формирования новых слов, так и путем переориентации уже существовавших на выражение новых значений. Весьма существенной оказалась 
также роль заимствований из других языков, и в первую очередь - из итальянского, ввиду того, что самый значительный по размаху и последствиям этап формирования вооруженных сил во Франции (XI в.) совпал по времени с эпохой тесных военных и культурных контактов с Италией, во многих отношениях опережавшей другие страны. При этом обнаруживалось порой значительное расхождение между первичным смысловым наполнением термина и его сегодняшним пониманием: объем значения одного и того же термина мог со временем либо сужаться, либо расширяться (как, например, объем значения слов «сарitaine» (капитан) и «maréchal» (маршал).

Особо хочется подчеркнуть следующее. Данная статья написана в расчете на лиц, для которых французский язык является неродным и которые, в отличие от франкофонов, не прослеживают достаточно полно и четко связи, существующие между отдельными лексическими единицами этого языка. Хотя, справедливости ради, следует заметить, что и в пределах русского языка лексические связи далеко не всегда являются достаточно отчетливыми для его носителей. Так, например, исконно русское слово «зодчий» практически не связывается с родственными ему «созидать» и «здание» в силу утраты русским языком слова «зbдb» («глина», то есть строительный материал), засвидетельствованного древнерусскими памятниками письменности [2].

Именно с этой категорией читателей - любителей словесности, и в первую очередь, словесности французской, - автор хотел бы поделиться возникавшей у него радостью открытия в хорошо знакомых, привычных, и поэтому в какой-то степени безликих, звуковых оболочках французских слов ясно ощутимой смысловой наполненности - процесса, позволяющего заглянуть под «внешнюю корочку» термина и, обеспечив ее прозрачность, то есть соотнеся с реально существовавшим денотатом, проследить за ходом мысли человека отдаленной эпохи и тем самым как бы оказаться свидетелем рождения новой терминологической единицы изучаемого языка. 
Начнем издалека, из окутанной дымкой времени далекой исторической эпохи.

Во времена галлов любой здоровый мужчина был воином (guerrier, $p p a н \kappa$. werra $=$ войнa $)$. На коврах из местечка Байё (Tapisserie de Bayeux) мы можем увидеть сидящего на высоком седле своего боевого коня франка. Он одет в кожаные доспехи, усиленные металлическими вставками, защищающими его с ног до головы. На голове - круглая каска с выступающим вперед наносником. Он вооружен копьем (lance, кельт. lancea = копье) и длинной шпагой (épée, spatha - слово неизвестного происхождения), в его руке - продолговатый щит (bouclier, слово, образованное путем эллиптирования термина «е́си à boucle» («е́си», лат. scutum $=$ щуит $и$ «boucle», лат. buсcиla $=$ пряжка).

C момента образования монархии франков (VI в.) вплоть до XV века армия была феодальной, то есть военная служба считалась обязанностью вассала перед господином, а король Франции был первым господином королевства. В зависимости от величины своих владений сеньоры (banneret, сеньор, имевщий право поднять знамя и собрать под ним своих вассалов (от «bаппіѐrе» = знамя, флаг, герман. bandwa) были обязаны по требованию господина поставлять на службу некоторое количество вооруженных и снабженных всем необходимым воинов (anspessade, дворянин, служивший в пехоте (om итал. lancia spezzata = сломанное (в бою) копье). Призыву на службу подлежали только дворяне. Однако существовала возможность использования в армии и представителей других сословий. Призыв в армию производился в границах каждой провинции отдельно и, как правило, требование о призыве распространялось на одну из них. Срок службы был ограничен рамками одной военной кампании (campagne, umaл. campania (om лат. campus = nоле), длившейся обычно около 40 дней, но мог и продлеваться в случае длительных маршей. К этому времени относится возникновение одного из первых воинских званий - корнет (cornette, лат. cornu = poг, poжок). Так называли воина, задачей которого было передавать команды начальника при помощи рожка. 
C IX века (при Каролингах) армия состояла, как правило, из вооруженных всадников. Однако, справедливости ради, следует заметить, что такое представление о средневековой армии сложилось на основе легенд и романов. Данные археологии опровергают утверждения о преобладающей роли кавалерии в XXI веках и неопровержимо свидетельствуют о том, что костяк армии составляли пехотинцы. Именно они начинали бой в первом эшелоне, обстреливая противника стрелами. В прорыв устремлялись пешие бойцы с копьями и шпагами. Задачей же кавалерии являлось развитие успеха и преследование противника [3].

В 807 г. Карл Великий требовал, чтобы каждый владелец надела земли, превышавшего 3 манса, выставлял в случае необходимости одного вооруженного всадника (chevalier, om «cheval», лат. caballus = кляча, вытеснившее классическое латинское equus = лошадь). При этом каждого всадника должны были сопровождать пешие слуги (milites, om лат. «miles» = coлдат, военный, от латинского слова «тіl» (тысяча), т.е. каждый из тысячи военнослужащчих, составлявиих древнеримский легион) и повозка (train, обоз, транспортные войска (от «traîner», лam. traginare = maщ̧umь за собой). Подсчитано, что таким образом Карл мог собирать до 10000 всадников для ведения своих ежегодных летних кампаний. Выплата денежных пособий не предусматривалась, средством к существованию военнослужащих были личные сбережения и деньги, вырученные от продажи захваченных в бою пленных. Иерархического командования не существовало: всадники от каждой провинции подчинялись своему местному начальнику из знати, который на период ведения военных действий получал титул герцога (duc, лат. $d u x=$ вождb, начальник). Для выполнения особых функций назначались прапорщчики (enseigne, воин, которому доверялось нести знамя (прапор), от лат. insignia = знак).

Примечание. Манс - участок земли, рассчитанный на работу одной пары волов.

После распада империи Каролингов единая централизованная армия распалась на княжеские отряды - крупные сеньоры получили возможность иметь свои собственные «армии», укомплектованные по традиционному принципу. Самая 
большая из этих армий насчитывала 50-60 человек. Исключение составляли крестовые походы, для которых церкви удавалось набирать до 40000 (а в отдельных случаях и до 100 000) человек, причем четвертую часть из них составляли всадники, то есть представители высшего сословия. Крестоносцы обмундировывались и вооружались за свой счет, что привело к разорению многих знатных семейств.

Военные действия между феодалами велись незначительными силами и по поводу споров местного значения: оборона замка, захват моста и т. п. Самые богатые сеньоры могли позволить себе организацию постоянной охраны своих замков: на стенах замков дежурили лучники (archer, лат. arcus = лук). Эти воины могли временно передаваться другому господину, в частности королю Франции, как это было в 1214 г., когда города провинции Бувин (Bouvines) послали своих воинов в распоряжение короля Филиппа II. Это событие считается отправной точкой в создании системы резерва (запаса) вооруженных сил Франции. Существует упоминание еще об одном историческом событии, имеющем отношение к массовому использованию резервов всей нации: при Капетингах (а именно при Людовике VI, короле Франции, 1108-1137) в 1124 г. вблизи Реймса была собрана национальная армия численностью в 300000 человек, которая одним своим присутствием расстроила планы английского короля по завоеванию Франции и разрушению Реймского собора.

При Филиппе II (король Франции, 1180-1223) французская монархическая власть стала достаточно сильной для того, чтобы мобилизовать в случае необходимости все военные силы королевства. Однако система комплектования оставалась феодальной: дворянство королевского домена сражалось под предводительством короля или его приближенных, становившихся на время военачальниками. Города (поместья) были обязаны предоставлять в распоряжение короля воинов, называвшихся обычно сержантами (sergent, слово образованнок от причастия настоящего времени латинского глагола servire (= служить), servire $\rightarrow$ serviens, servientis = находящийся на службе). Одни из них служили под начальством королевского уполномоченного, другие подчинялись своим местным 
должностным лицам. По окончании военных действий сержанты переходили в распоряжение городов (служба по охране замков).

Примечание. Обратите внимание на имеющее здесь место фонетическое чередование - замена фонемь $[v] \rightarrow[\dot{g}]:$ servientis $\rightarrow$ sergent. Cp. savant $\rightarrow$ sage.

Такое положение сохранялось во Франции вплоть до XIV в. - постоянно действующей армии практически не существовало. Определенным исключением был период Столетней войны (1337-1558): собранное войско не распускалось на зиму, а удерживалось в определенном месте в виду очередной кампании. Эти войска получили название роты (compagnie, лаm. paзz. compania), и прозвище «бандиты» (bandit, om bande, групnа вооруженных людей), поскольку, не получая денежного содержания, они существовали за счет местного населения.

Примечание. Слово «сотрапіа» образовано от лат. существительного «pan, panis»= хлеб и приставки «сот-», обозначающей совместность действия, т.е. в буквальном смысле те, кто ест хлеб сообща. В современном понимании обозначает воинское подразделение и переводится на русский язык как «рота».

Слово «bаnde» образовано от старофраниузского «bап» = призыв на военную службу, обращуенный сюзереном к своим вассалам.

Указом Карла VII (король Франции, 1422-1461) от 2 ноября 1439 года была установлена постоянная статья бюджета государства (1 200000 ливров в год), формируемая за счет сбора податей и предназначенная для организации и содержания постоянной королевской армии, имеющей свой собственный бюджет и постоянный кадровый состав. В 1448 г. Карл VII создал отряды «Свободных стрелков» (Francs Archers u Francs Tireurs). Эти отряды состояли из резервистов, проходивших военную подготовку в выходные дни и служивших лично королю. Эффективность их использования была очень низкой: во время битвы при Гинегатте (1479) 16-ти тысячное войско резервистов (Francs Tireurs) сбежало с поля боя. Таким образом, эта армия еще не была постоянной в нынешнем понимании этого слова. Постоянным был только ее командный состав: командиры частей (саріtaine, термин, образованный от позднелатинского слова сарitaneus (начальник) на основе латинского слова caput, capitis = голова) назначались королем и 
оплачивались за счет средств армии. Важным положительным следствием Указа Карла VII явилась возможность создания артиллерии (artillerie), за счет централизованных денежных средств (королевский бюджет), чего не могли себе позволить не имевшие подобных средств сеньоры.

Примечание. Интересна судьба этого термина: в средние века он имеет значение «полководеи, военачальник, командир», а в наше время обозначает одно из воинских званий младиих офицеров (в иерархии французских званий находится между званиями «лейтенант» (lieutenant) и «майором» (commandant), сохраняя при этом свое первоначальное значение (как правило, в переносном смысле: «Les grands capitaines de la nation»). В качестве воинского звания используется с 1445 г. В армии Карла VII было 28 капитанов, которые командовали 16000 лучников (по 500-600 на каждого) под руководством 2-3 главных капитанов (capitaine général, om лат. generalis = общчий, охватываюший всех). С созданием легионов (1000 человек) при Франциике I командуют ими, а затем, с введением звания «полковник» (colonel), командуют ротами. Прилагательное «général» со временем субстантивируется и станет обозначать особое воинское звание «генерал», начиная с XVIII в.

Термин образован от глагола германского происхождения attilier (снабжать военными устройствами) и изменен по аналогии со словом аrt (oт лат. ars, artis $=$ искусство).

Кавалерия, не способная отныне успешно противостоять пушкам, постепенно заменялась пехотой, служба в которой считалась поначалу недостойной звания дворянина: это стало причиной создания наемных французских или иностранных (в частности, швейцарских) воинских частей. С приходом к власти Людовика IX (король Франции, 1461-1483) пехота (infanterie, om um. infanteria, om um. infante = ребенок) занимает главенствующие позиции на поле боя, на ее вооружении появляется огнестрельное оружие: аркебузы (arquebuse) и мушкеты (mousqueton). 
Примечание. Имеется в виду наследник престола, который имел право командования самым лучшим (и в новых условиях самым престижным) видом вооруженных сил.

В этот период начинают широко использоваться термины «солдат» (soldat) и «капрал» (caporal) для обозначения воинских званий рядового состава (hommes du rang).

Слово «soldat» существует с 1475 г. и обозначает военнослужащего, получающего денежное содержание за свою службу (то есть служащего постоянно, а не временно). Оно заимствовано из итальянского языка, где является причастием настоящего времени от глагола «soldare» (платить) - «soldato» (от лат. solidus = денежная единица, солид, производное от прилагательного solidus = плотный, твердый). Существовавшая параллельно французская форма «souldar» постепенно вышла из активного употребления, и сегодня термин «soudard» (грубый солдафон) представляет собой ярко окрашенный стилистически термин разговорной речи.

Примечание. Ср. современное итальянское слово «soldi» (деньги).

Слово «сарoral» образовано в 1558 г. от латинского слова «саput, capitis» (голова) для обозначения старшего в отделении солдат (10-12 человек). Оно имеет современное звучание благодаря посредничеству итальянского языка (ит. caporale).

Первые французские полки постоянного штата (в которых постоянен не только командный, но и рядовой состав) появились только при Франциске I (король Франции, 1515-1547), который именовал их на древнеримский манер (начиналась эпоха Возрождения!) легионами (légions, om лат. legio, legionis (легион), от лат. глагола lego (собирать, набирать). Во второй половине XVI в. Эти воинские части получили иное, сохранившееся до наших дней название - «полки» (régiment, oт лат. rеgо (командовать, управлять), от лат. rex, regis (царь).

Командование полками считалось выполнением обязанностей королевской службы (offices), и поэтому исполнявшие их лица назывались офицерами 
(officiers, om лат. officiarius (исполняющий поручение, должность), от лат. officium (должность).

Примечание. Ср. русское слово «официальный», то есть связанный с занимаемой по праву должностью, должностной.

В течение XVII в. военные должности претерпевали те же изменения, что и гражданские: исполнявшие эти должности лица становились собственниками подчиненных и своего собственного звания. Должности отныне могли подлежать продаже и покупке (ввиду нехватки средств в казне) или передаваться другим лицам по наследству. Военнослужащие, командовавшие крупные военными отрядами получили наименование «полковник» (colonel) и «подполковник» (lieutenant-colonel).

Воинское звание «colonel» (полковник) образовано от итальянского слова «colonello» на основе слова «colonna» (колонна, то есть совершающая марш воинская часть). Этому термину предшествовал другой, ныне забытый и не использующийся, также образованный по итальянскому образцу - «mestre de camp» (om um. maestro di campo, где слово «сатро» означало «поле боя»).

История же воинского звания «lieutenant-colonel» (подполковник) весьма любопытна. Как уже было сказано выше, звание «полковник» (colonel) закрепляется в армии в 1661 г., когда полки стали передаваться по наследству или покупаться. Такое положение объяснялось тем, что неумеренная роскошь и всевозможные излишества двора Франциска I привели к опустошению королевской казны. Одним из путей ее пополнения и стала продажа государственных должностей. В свою очередь это привело к тому, что зачастую формальным командиром полка оказывался либо ребенок, либо юноша, родители которого покупали полк и записывали его на имя своего сына. Для осуществления реального командования назначались военнослужащие зрелого возраста, которые как бы «занимали место» полковника (tenaient lieu du colonel, от французского оборота «tenir lieu» (занимать место, замещать). Так возникло еще одно воинское звание «lieutenant-colonel» (глагол стоит в форме причастия настоящего времениtenant). 
Ту же роль выполняли опытные заместители и при капитанах. Так было образовано звание «lieutenant-capitaine», давщее впоследствии, при усложнении военной организации, звание «lieutenant» (лейтенант) и «sous-lieutenant» (младший лейтенант) путем использования в последнем случае французского предлога «sous» (под).

Примечание. Остающееся и по сей день в Военно-Морском флоте России (капитан-лейтенант).

Таким образом, армия становится вновь в некотором роде феодальной: сеньор-командир (а значит и владелец) полка или роты обязан обеспечивать выполнение определенных обязанностей в военное время. При этом он оставался полным хозяином в том, что касалось выплаты денежного содержания, соблюдения дисциплины, назначений на должности. Все это создавало благоприятную почву для злоупотреблений. В 1660 г. вводятся периодические смотры частей для проверки готовности офицеров к выполнению своих обязанностей и состояния войск. Однако лазейки для очковтирательства находятся быстро - в дни смотров в строй становятся подставные лица.

К этому же периоду относится рождение еще одного воинского звания «сержант артиллерии» (maréchal des logis), которое проделав «головокружительную карьеру», станет со временем обозначением высшего должностного лица в военной иерархии - «мармал» (maréchal). Дело в том, что при Генрихе II (1550 г.) воскрешается почти забытый термин германского происхождения времен нашествий франков IV-VI вв. - maréchal (om герм. marnskalk = cлуга, yхаживающий за лошадью). Этим словом стали называть в артиллерии лиц, ответственных за «транспорт», перевозивший орудия - лошадей. В этом значении термин существует и по сей день во французских вооруженных силах - «maréchal des logis» (logis в одном из значений = конюшня, от герм. laubja = нора животного) и означает воинское звание «сержант артиллерии».

Параллельно с этим, в XVI в. происходил процесс расширения значения этого слова, которое начало использоваться для названия лиц, занимавшихся 
снабжением армии, ведущей боевые действия. Это звание получали знатные приближенные короля, стремившиеся к постоянному расширению своих полномочий и усилению своего влияния в армии и при дворе, что и привело, в конечном счете, к современному пониманию термина- - самый главный военнослужащий»-«маршал Франц̧ии» (maréchal de France).

Кроме того, соперничество среди маршалов при дворе Генриха II привело к тому, что один из них получал право называться «главным» (major, om сравнительной степени латинского прилагательного таgnus = большой). Со временем слово «тајor» субстантивируется (как и слово «général») и становится самостоятельным термином - «майор» (major). Однако во французской армии это звание, употребляющееся в вооруженных силах многих государств, не получило широкого распространения и используется лишь для обозначения лиц, занимающих военно-административные должности, в частности военно-медицинские.

Как уже было отмечено выше, воинское звание «генерал» (général) явилось результатом субстантивации прилагательного «général» (общий), относившегося первоначально к воинскому званию «сарitaine»- «capitaine général». В качестве самостоятельно существующего термина оно стало употребляться для обозначения лиц, командующих крупными войсковыми единицами - бригадами, дивизиями, корпусами и армиями, получая в этих случаях необходимое уточнение: «général de brigade» (бриргадный генерал), «général de division», (дивизионный генерал), «général de corps d'armée» (корпусный генерал), «général d'armée» (apмейский генерал).

Более того, со временем во французской армии появилось новое «суперзвание» - «генералиссимус» (généralissime), которое было образовано как превосходная степень прилагательного «général».

Примечание. Во франщузских вооруженных силах этого звания были удостоены Фердинанд Фош (1918 2.), Морис Гамлен (1939 г.) и Филипп Петэн (1940 2.).

Для военно-морского флота высшим воинским званием стало звание «адмирал» (amiral), образованное в 1270 г. при Карле Анжуйском, короле Неаполя, на 
основе заимствованного из арабского языка словосочетания «атir al bahr» (= морской начальник).

Вернемся, однако, в XVII век и продолжим наше повествование.

В 1668 г. Лувуа (помощник государственного секретаря по военным вопросам при Людовике XIV) создает народное ополчение (milices, om лam. militia= военная служба (om лат. miles, militis = военный), то есть систему набора в военное время добровольцев (а при нехватке добровольцев - по жребию) для усиления армии со сроком службы два, а затем шесть лет. Собранные таким образом войска предназначались для охраны городов и участия в боевых действиях. После подписания Рисвикского мирного договора в 1697 г. милиция была распущена и воссоздана в 1700 г. во время войны за испанскую корону, и с этого момента «милиционеры» уже не являлись отдельными частями, а представляли собой скорее ресурсы для призыва на службу. Система набора по жребию становилась все менее популярной и давала повод для многочисленных вспышек недовольства. В марте 1791 г. милиция, ставшая почти ненавистной народу, была распущена. В результате страна лишилась мощного вооруженного корпуса и подготовленных резервов, что было чревато серьезными последствиями в силу обострения международной обстановки.

После Великой Французской революции, в 1791 г. был издан декрет о свободной записи в национальную гвардию, предусматривавший увеличение численного состава армии. Победа над прусскими войсками под Вальми (Valmy) стала символом торжества патриотического духа нации. В 1793 г. впервые в истории страны был принят закон об обязательном привлечении к военной службе всех граждан мужского пола в возрасте от 18 до 25 лет, который получил наименование закона о воинской повинности в 1798 г. Усилиями Лазаря Карно, французского математика, члена комитета национального спасения, создателя вооруженных сил Первой Республики, удостоившегося славного прозвища «организатор победы» (l'organisateur de la victoire), была произведена реорганизация армии - созданы 14 революционных армий. Наполеон насаждает в них дисциплину 
и наводит порядок в системе воинских званий. Получают регулярное употребление звания «генерал» (général), «капитан»(capitaine), «лейтенант» (lieutenant). Кроме того, при Наполеоне уже существовавшее слово «марmал» (maréchal) приобретает расширенное значение «полководец» (маршалы Наполеона).

Примечание. 26 маршалов Первой империи (1804-1814 г2.) во Франциии (А. Массена, Л.Н. Даву, Л.А. Бертье, Л.Г. Сюше, Ж.Б. Журдан, Л.Г. Сен-Сир, Ж.Э. Макдональд, Н.Ж. Сульт, Н.Ш. Удино, О.Ф. Мармон, Э. Груши и другие).

Для обозначения лиц, командовавших вновь созданными структурными единицами усложнившейся военной организации - батальонами, вводятся особые воинские звания, переводимые на русский язык равнозначным по объему значения словом «майор». Такими званиями становятся «chef de bataillon» (в пехоте) и «chef d'escadron» (в бронетанковых войсках и в артиллерии). Параллельно с этим вводится в обращение слово «commandant» (om глагола «commander» (командовать), используемое для обращения к этим должностным лицам.

Примечание. Как уже отмечалось, слово «тајог» используется для обращения к военврачу. Примечательно, что при обращуении к нему следует говорить не «Mon commandant!», a просто «Major!» (притяжательное местоимение «mon» опускается).

В 1818 г. Лоран Гувьон Сен-Сир (маршал Франции, военный министр Людовика XVIII) выдвинул проект строительства вооруженных сил, который стал зародышем ныне существующей армии. Суть новой системы заключалась в следующем: для поддержания боеготовности сильной постоянной армии вводился ежегодный призыв на службу 40000 молодых людей (выбираемых по жребию) на шестилетний срок. По возвращении домой эти молодые люди были обязаны находиться в течение 5 лет в распоряжении министра обороны. Это положение о пятилетнем пребывании в запасе было вскоре отменено законом 1824 г.

Усиление военной мощи Пруссии и очевидная необходимость повышения боеготовности французской армии стало стимулом принятия в 1868 г. Закона Ньеля (Адольф Ньель, военный министр Франции), в соответствии с которым в 
стране должна быть создана 400 000-ная действующая (постоянная) армия и подготовлено 800000 обученных резервистов. Этот закон был хорош лишь на бумаге - для его выполнения нужны были немалые средства, и их недостаток стал причиной военного поражения Франции в 1870 г.

Урок не прошел даром. С 1885 г. вводится в действие закон, который обязывает всех французов проходить действительную военную службу и службу в запасе. Наконец-то осознается необходимость иметь в запасе не только рядовых и унтер-офицеров («аджюдан» (adjudant) и «аспирант» (aspirant). В течение последующих лет были приняты различные поправки и уточнения к закону о всеобщей воинской повинности, что принесло свои плоды - победу Франции в 1-ой мировой войне.

Примечание. Термин «adjudant» образован через посредничество испанского языка, где соответствующая должность (помощуник командира в бою) звучит как «ауиdante»-от испанского глагола «ауиdar» (помогать). Ср. русское слово «адъютант».

Термин «аspirant» образован от французского глагола «аspirer» (cтремиться) и обозначает лиц унтер-офицерского состава, проходящчих подготовку к сдаче экзамена на звание младшего офицера (то есть - «стремящийся занять должность»).

Следует отметить многозначность термина «armée»: I. в единственном числе: 1) армия, войска, вооруженные силы (собирательное значение); 2) вид вооруженных сил (сухопутные войска (Armée de terre), BBC (Armée de l'air), BMC (Armée de mer); 3) армия (как войсковое соединение). II. во множественном числе: вооруженные силы (от лат. arma = оружие).

В период с 1920 по 1935 гг. сухопутные войска утрачивают способность к ведению военных действий за пределами метрополии, ограничив свою роль обучением запаса. Эта ошибка в совокупности с некоторыми другими промахами в подготовке кадрового состава армии привела к поражению страны в 1940 г.

После 2-ой мировой войны вооруженные силы неоднократно подвергались различным реорганизациям: в частности, из организационной структуры были 
устранены бригады (brigade, om um. brigata = войско) и батальоны (bataillon, om фp. bataille (= сражение).

Начиная с 2000 года во Франции реализуется очередная реформа вооруженных сил, получившая название «Вооруженныле сильл в 2000 2.» (Armées-2000). Отменен призыв молодежи на действительную военную службу, части и соединения формируются исключительно на профессиональной (контрактной) основе. Однако, само собой разумеется, освещение этих вопросов выходит далеко за рамки нашего историко-лингвистического исследования.

Примечание. Следует отметить многозначность термина «агте́е»: I. В единственном числе: 1) армия, войска, вооруженные сильл (собирательное значение); 2) вид вооруженных сил (сухопутные войска (Armée de terre), BВC (Armée de l'air), ВMC (Armée de mer); 3) армия (как войсковое соединение). II. Во множественном числе: вооруженные силь (от лат. агта = оружие).

\section{Приложение 1}

Воинские звания франиузских вооруженных сил

\begin{tabular}{|l|l|}
\hline \multicolumn{1}{|c|}{ Cухопутные войска-Armee de terre } & \multicolumn{1}{c|}{ Bоенно-морские силь-Armeе de mer } \\
\hline Soldat de 2-e classe & Matelot \\
\hline Soldat de 1-re classe & Matelot breveté \\
\hline Caporal* & Quartier-maitre de 2-e classe \\
\hline Caporal-chef* & Quartier-maitre de 1-re classe \\
\hline Sergent PDL (pendant la durée légale)* & Second maitre PDL \\
\hline Sergent ADL (après la durée légale)* & Second maitre ADL \\
\hline Sergent-chef* & Maitre \\
\hline Adjudant & Premier maitre \\
\hline Adjudant-chef & Maitre principal \\
\hline Major & Major \\
\hline Aspirant & Aspirant \\
\hline Sous-lieutenant & Enseigne de vaisseau de 2-e classe \\
\hline Lieutenant & Enseigne de vaisseau de 1-re classe \\
\hline Capitaine & Lieutenant de vaisseau \\
\hline Chef de bataillon* & Capitaine de vaisseau \\
\hline Lieutenant-colonel & Capitaine de frégate \\
\hline Colonel & Capitaine de vaisseau \\
\hline Général de brigade & Contre-amiral \\
\hline Général de division & Vice-amiral \\
\hline
\end{tabular}




\begin{tabular}{|l|l|}
\hline Général de corps d'armée & Vice-amiral d'escadre \\
\hline Général d'armée & Amiral \\
\hline Maréchal de France & - \\
\hline
\end{tabular}

* Звания, отмеченные звездочкой, в артиллерии и бронетанковых войсках обозначаются особыми терминами: соответственно - caporal = brigadier, caporal-chef $=$ brigadier-chef, sergent $=$ maréchal des logis, sergent-chef $=$ maréchal des logis-chef, chef de bataillon = chef d'escadron .

\section{Список литературы}

1. Падучева Е.В. Высказывание и его соотнесенность с действительностью (референциальные аспекты семантики местоимений). - 2-е изд. - М.: Эдиториал УPCC, 2001. - C. 103.

2. Чигашева М.А. Семантическое поле воинских званий в русском и немецком языках: Дис. ... канд. филол. наук. - М., 2003.

3. Откупщиков Ю.В. К истокам слова. Рассказы о науке этимологии. - М.: Книга, 2015. - С. 3.

4. Дельбрюк Г. История военного искусства. Средневековье. Новое время. Русич, 2003.

5. Функен Л. Средние века. Эпоха Ренессанса: Пехота - кавалерия - артиллерия / Лилиана Функен, Фред Функен. - М.: АСТ; Астрель, 2002.

6. Вооруженные силы основных капиталистических государств / С.И. Анжерский, С.И. Семенов, И.Ф. Скридлевский [и др.]; под ред. С.И. Беркутова. М.: Воениздат, 1988

7. Чернышев В. Воинские звания и военная форма одежды // Основы безопасности жизнедеятельности. - 1999 а. - №6.

8. Le Petit Robert de la langue française, sous la direction de J. Rey-Debove et A. Rey, 2015.

9. Le Petit Larousse illustré 2015, Éditions Larousse.

10. Le Littré, Éditions du Cap, jusqu'en 2003.

11. Atilf [Электронный ресурс]. - Режим доступа: http://atilf.atilf.fr/tlf.htm

12. Cnrtl [Электронный ресурс]. - Режим доступа: http://www.cnrtl.fr/ 
13. Grades de l'Armée française // Wikipédia [Электронный ресурс]. - Режим доступа: https://fr.wikipedia.org/wiki/Grades_de_l'Arm\%C3\%A9e_fran\%C3\%A7aise

14. Dictionnaires et Encyclopédies sur 'Academic' [Электронный pecypc]. - Peжим доступа: http://fr.academic.ru/dic.nsf/frwiki/1022603

Лядский Владимир Георгиевич - старший преподаватель факультета иностранных языков и регионоведения ФГБОУ ВО «Московский государственный университет им. М.В. Ломоносова», заведующий кафедрой гуманитарных дисциплин и коммуникационных технологий НАНО ВО «Институт мировых цивилизаций», Россия, Москва.

Lyadsky Vladimir Georgievich - senior lecturer of the Department of Foreign Languages and Regional Studies FSFEI of HE "M.V. Lomonosov Moscow State University", head of the Department of Humanities and Communication Technologies PANO of HE "Institute of World's Civilizations", Russia, Moscow. 